\title{
La entrevista al artista en las fichas de catalogación de arte urbano como método de conservación preventiva
}

Sergio Cruz Molina | Estudiante de historia del arte, Universidad de Jaén

URL de la contribución <www.iaph.es/revistaph/index.php/revistaph/article/view/4914>

Desde sus comienzos en los años 60 del siglo $X X$, el arte urbano se ha caracterizado por su faceta ilegal. Una faceta que le ha conferido una mala fama entre los ciudadanos pero, a la vez, garantizado el acceso a sus ojos y memoria. Esta, en la mayoría de las ocasiones, constituye el principal medio de conservación de muchas de las obras de arte urbano que encontramos por el mundo. Se le suma, en la actualidad, la instantánea subida a redes sociales que, si bien garantiza de alguna manera el registro fotográfico inmediato, esa misma inmediatez intrínseca a las redes provoca que también rápidamente queden relegadas al olvido.

A pesar de todo, en los últimos años se ha producido una revalorización del arte urbano, tanto a nivel social como institucional, que plantea la posibilidad de la patrimonialización de este tipo de expresiones artísticas.

Estas producciones están marcadas, además, por la espontaneidad de su emplazamiento en cualquier lugar del espacio público. Los artistas prefieren determinados lugares para realizar sus obras, pero cualquier sitio puede resultar bueno para ejecutar un mural de mayor o menor complejidad. Por esta razón, por ubicarse en cualquier lugar, nos encontramos una obra muy desprotegida, expuesta a la intemperie callejera. Esto nos lleva a pensar en una obra efímera que desaparecerá del muro, bien por el paso del tiempo, porque el propietario decida reconfigurarlo o porque otro artista pinte otra obra. Hay tantos motivos para la desaparición de

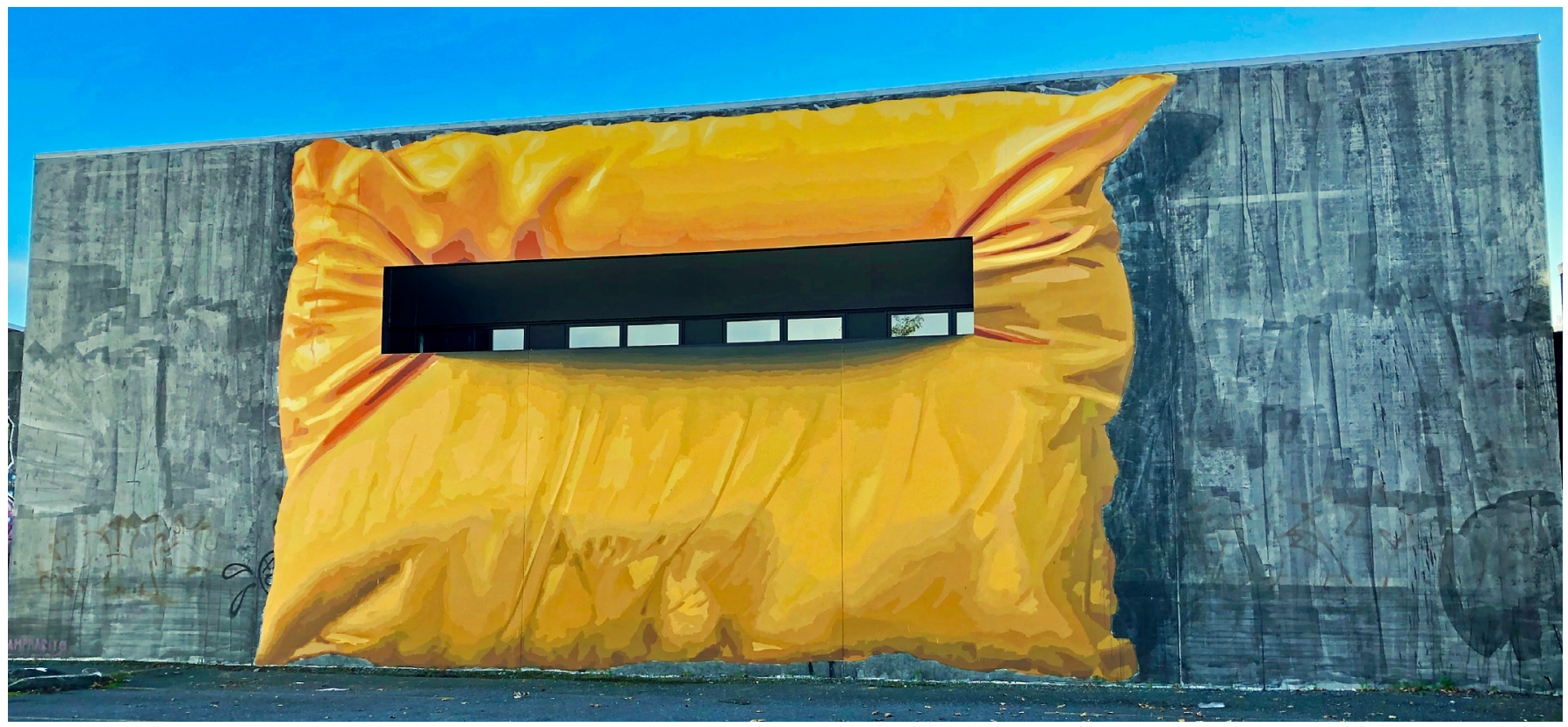

Pillow Fight. Ampparito | foto Chris Christian 
una obra como personas pasan cerca de ella. De hecho, el propio concepto de arte urbano implica lo efímero, pues están en diálogo con la propia ciudad y con las comunidades que la habitan, al margen del muralismo por encargo que ha emergido en los últimos años, que puede tener otra razón de ser.

De esta manera los viandantes se convierten en la principal fuente de conservación. Pero tal vez la permanencia de las obras en la memoria puede registrarse mediante la catalogación y esto constituye un primer paso para su subsistencia. Resulta importante elaborar una ficha de catalogación que vaya documentando las diferentes apariciones de las múltiples obras en cada ciudad. Una ficha que registre este tipo de obra, tan fugaz, de una manera más dinámica aún, buscando la adaptabilidad de los estudiosos a esta nueva forma de hacer arte. Una ficha que permita ir reconociendo las diferentes obras que van apareciendo y en qué lugar se localizan, hasta el punto de saber en cada momento qué obra había en cada lugar debido a la posible desaparición de una pieza y la aparición de otra nueva.

Igualmente sería importante que esa ficha incluya una entrevista al artista para poder conocer las particularidades de cada obra en su contexto urbano, que es lo que la carga de sentido. La entrevista se convertiría en una herramienta de recolección de información directa del autor que, además de permitirnos profundizar en el contenido, ayudaría a futuros restauradores a intervenir en la obra respetando los deseos del artista. Trabajan con la entrevista algunas autoras como Ana Lizeth Mata Delgado (2019), que propone una metodología de trabajo basada en el diálogo con los artistas para conocer su perspectiva en relación con la creación de los museos de arte urbano.

Por otro parte, Elena García Gayo (2016) propone la redacción de un "testamento" elaborado con el o la artista, que deje claro el proceso de degradación o de mantenimiento que se quiere para la obra. En este sentido, por ejemplo, el artista Ampparito, en el I simposio internacional Reflejos de arte urbano y público, cele-

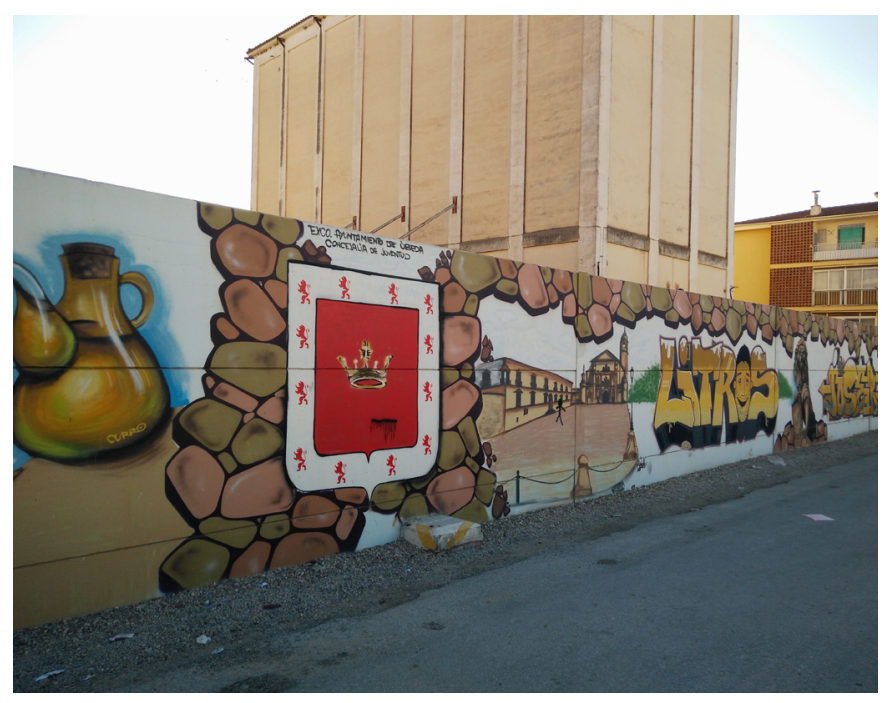

Mural de Úbeda, Jaén | foto JJ Melero

brado en septiembre de 2020 , contaba cómo considera que su obra se termina a medida que se degrada con el paso del tiempo, pues la integra mejor en el contexto. La catalogación anterior nos serviría para tener un registro y acumular un conocimiento de la actividad artística del arte urbano en cada ciudad y proyectar la idea de vida de la obra. La entrevista (García Gayo et ál. 2019, 255-325) se convierte en una fuente de información muy interesante sobre el artista, su obra, su forma de trabajar, incluso sobre la documentación del proceso creativo. Además ayuda a la salvaguarda de unas obras que no están protegidas, en principio, de ninguna manera.

Asimismo, en la propuesta de ficha de catalogación de Maribel Úbeda (2016), la entrevista al artista se contempla como un apartado importante, aspecto en el que coincide con Luque Rodrigo y Moral Ruiz (2016), que la proponen para otro tipo de expresiones artísticas actuales de difícil conservación. La entrevista no ha sido clásicamente relevante en la catalogación de obras de arte; sin embargo, supone un paso clave para profundizar en el conocimiento del movimiento artístico y de lo que la mente creadora ha previsto en relación con su obra. Como ejemplo práctico de la utilización de entrevistas, en el proyecto de investigación Pintado en la pared: estudio de la pintura sobre muro de los siglos XX y XXI en la 
provincia de Jaén, financiado por el Instituto de Estudios Giennenses, en el que participo, se está poniendo en práctica la utilización de una ficha que incorpora este apartado dedicado a la opinión de los artistas.

De cara a la toma de decisiones sobre su patrimonialización y las posibles intervenciones para su conservación, aún faltaría por incorporar otro punto clave y más complejo: la relación de la comunidad con la obra.

\section{BIBLIOGRAFÍA}

- García Gayo, E., Gracia Melero, S., Senserrich-Espuñes, R., García Melero, S., Santabárbara Morera, C., Pallarès, J. y Gasol, R.M. (2019) Anexo: Arte urbano y Museo. Competencias e (in)compatibilidades. Ge-conservación, n. ${ }^{\circ}$ 16, pp. 255-325. Disponible en: https://ge-iic.com/ojs/index.php/revista/article/ view/717/927 [Consulta: 23/04/2021]

- García Gayo, E. (2016) Etapas del Arte Urbano. Aportaciones para un Protocolo de conservación. Ge-conservación, n. ${ }^{\circ} 10$, pp. 97-108. Disponible en: https://ge-iic.com/ojs/index.php/ revista/article/view/401 [Consulta: 11/04/2021]

- Luque Rodrigo, L. (2020) La gestión del arte urbano, ¿una cuestión pendiente? La Colmena: Revista de la Universidad Autónoma del Estado de México, n. ${ }^{0} 106$, abril-junio 2020, pp. 81-98. Disponible en: https://lacolmena.uaemex.mx/article/ view/13191 [11/04/2021]

- Luque Rodrigo, L. y Moral Ruiz, C. (2016) Proposal for the establishment of a protocol for documentation of contemporary art why is necessary a new protocol. Póster. $\mathrm{V}$ Conferencia Internacional YOCOCU 2016. Disponible en: https://www.academia.edu/38751417/PROPOSAL FOR_THE_ESTABLISHMENT_OF_A_PROTOCOL_FOR_ DOCUMMENTATION OF CONTEMPŌRARY ART_WHY IS NECESSARY_A_NEWW_PROTOCOL [Consulta: 21/04/2021]

- Mata Delgado, A.L. (2019) La postura del artista ante los museos de arte urbano en el contexto latinoamericano. Arte urbano y Museo. Competencias e (in)compatibilidades. Geconservación, n. ${ }^{\circ}$ 16, pp. 193-203 Disponible en: https://www. ge-iic.com/ojs/index.php/revista/article/view/708 [Consulta: 18/04/2021]

- Úbeda García, M.I. (2016) Propuesta de un modelo de registro para el análisis y documentación de obras de arte urbano. Ge-conservación, n. ${ }^{\circ}$ 10, pp. 169-179 Disponible en: https://www.ge-iic.com/ojs/index.php/revista/article/view/410/ pdf [Consulta: 21/04/2021] 